\title{
Heavy-atom effects on metalloporphyrins and polyhalogenated porphyrins
}

\author{
Emília G. Azenha ${ }^{\mathrm{a}}$, Arménio C. Serra ${ }^{\mathrm{b}}$, Marta Pineiro ${ }^{\mathrm{a}}$, Mariette M. Pereira ${ }^{\mathrm{a}}$, \\ J. Seixas de Melo ${ }^{\mathrm{a}}$, Luis G. Arnaut ${ }^{\mathrm{a}, *}$, Sebastião J. Formosinho ${ }^{\mathrm{a}, 1}$, \\ A.M.d'A. Rocha Gonsalves ${ }^{a}$ \\ ${ }^{a}$ Chemistry Department, University of Coimbra, 3049 Coimbra Codex, Portugal \\ ${ }^{\mathrm{b}}$ Universidade Católica Portuguesa, P-3080 Figueira da Foz, Portugal
}

Received 23 January 2002; in final form 18 March 2002

\begin{abstract}
The photophysics of halogenated and metallated tetrakisphenylporphyrins is investigated using single-photon counting, photoacoustic calorimetry and luminescence techniques. The radiationless transition rates in these and related molecules are interpreted with a quantum-mechanical tunnelling model modified to include the effect of spin-orbit coupling in the intersystem crossing rates. It is shown that tetrakisphenylporphyrins with halogens in the ortho positions have long-lived triplet states that are formed in high yields. (c) 2002 Elsevier Science B.V. All rights reserved.
\end{abstract}

Keywords: Porphyrins; Radiationless transitions; Tunnel-effect theory; Heavy-atom effect

\section{Introduction}

Porphyrin derivatives represent an important class of pigments in the storage of energy in both natural and artificial photosynthesis [1-4], on the making of molecular energy devices [5,6], catalysts [7], and more recently as sensitisers of specific products (e.g., the singlet ${ }^{1} \Delta_{\mathrm{g}}$ state of molecular oxygen) in photodynamic therapy (PDT) [8-10]

\footnotetext{
${ }^{*}$ Corresponding author. Tel.: +351-39-822826; fax: +351-39827703.

E-mail address: lgarnaut@ci.uc.pt (L.G. Arnaut).

${ }^{1}$ Present address: Escola Superior de Ciências e Tecnologia, Universidade Católica Portuguesa, 3500 Viseu (Portugal).
}

and in the photodynamic destruction of viruses $[11,12]$. The present work was motivated by the need for better PDT sensitisers based on porphyrins, chlorins and bacteriochlorins [13-15], that is, sensitisers with high absortivity in the phototherapeutic window $(600-900 \mathrm{~nm})$ that generate singlet oxygen in high yields. The most important precursor of the $\mathrm{O}_{2}\left({ }^{1} \Delta_{\mathrm{g}}\right)$ state is the triplet state $\mathrm{T}_{1}$ of the sensitiser. Therefore, an ideal sensitiser must have a long-lived triplet state $\left(\tau_{\mathrm{T}}>5 \mu \mathrm{s}\right)$ formed in high yields $\left(\Phi_{\mathrm{T}} \approx 1\right)$, and a triplet energy at least $20 \mathrm{~kJ} \mathrm{~mol}^{-1}$ above that of the $\mathrm{O}_{2}\left({ }^{1} \Delta_{\mathrm{g}}\right)$ state $\left(E_{\mathrm{T}}>115 \mathrm{~kJ} \mathrm{~mol}^{-1}\right)$.

In order to maximise the quantum yield for triplet formation one usually resorts to an internal heavy-atom effect [16]. A quite extensive research 
has been undertaken on the study of such effects in halogenated porphyrins and metalloporphyrins $[1,13,17-19]$. In this work we have revisited some old data and supplement it with studies on new molecules. We present the energies and quantum yields $(\Phi)$ of formation of $\mathrm{S}_{1}$ and $\mathrm{T}_{1}$ states of halogenated tetrakisphenylporphyrins and zinctetrakisphenylporphyrins, and other metallotetrakisphenylporphyrins (MeTPP) (Scheme 1) together with their lifetimes $(\tau)$ and intersystemcrossing rate constants $\left(k_{\text {isc }}\right)$. This systematic study of heavy-atom effects is rationalised through the use of a model for radiationless transitions in large molecules [20]. The application of this model reveals trends that may be useful in the design of new molecules with pre-required properties.

\section{Experimental}

All solvents and reagents were purified using standard procedures.

\subsection{Instrumentation and methods}

The ${ }^{1} \mathrm{H}$ NMR spectra were recorded with a 300 $\mathrm{MHz}$ Bruker-AMX spectrometer. Mass spectra were obtained on VG autospec and elemental
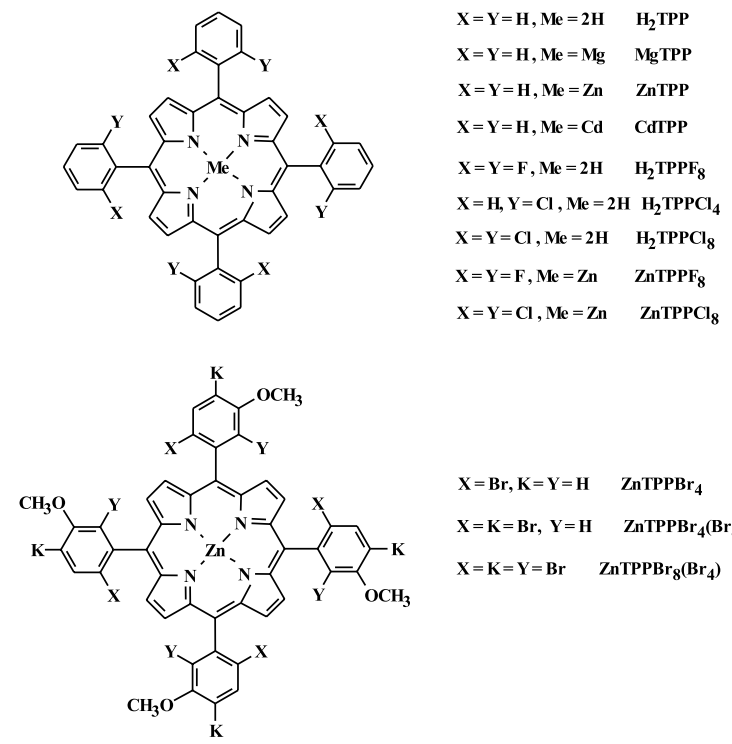

$\mathrm{X}=\mathrm{Br}, \mathrm{K}=\mathbf{Y}=\mathbf{H} \quad \mathrm{ZnTPPBr}_{4}$

$\mathrm{X}=\mathrm{K}=\mathrm{Br}, \mathbf{Y}=\mathbf{H} \quad \mathrm{ZnTPPBr}_{4}\left(\mathrm{Br}_{4}\right)$

$\mathrm{X}=\mathrm{K}=\mathrm{Y}=\mathbf{B r} \quad \mathrm{ZnTPPBr}_{\mathbf{8}}\left(\mathrm{Br}_{4}\right)$

Scheme 1. Porphyrins and metalloporphyrins used in this work. analysis on EA1108-CHNS-0 Fisons Instruments. Absorption and luminescence spectra were recorded with Shimadzu UV-2100 and SPEX fluoromax 322-2 spectrophotometers, respectively. Home-made equipment was employed in singlephoton counting and photoacoustic calorimetry measurements.

All the solutions were carefully de-aerated with $\mathrm{N}_{2}$ saturated in toluene before the photophysical measurements were made.

Fluorescence quantum yields $\left(\Phi_{\mathrm{F}}\right)$ were determined as described previously [13], with excitation at the maximum of the Soret band. Fluorescence excitation spectra were obtained for all the porphyrins and metalloporphyrins and agreed well with the corresponding absorption spectra. The phosphorescence studies were carried out in toluene at liquid nitrogen temperature, with excitation at the Soret band.

Fluorescence lifetimes were measured with an apparatus using an IBH 5000 coaxial flashlamp, filled with $\mathrm{N}_{2}, \mathrm{D}_{2}$ or $\mathrm{H}_{2}$ (or mixtures of them), as excitation source, Philips XP2020Q photomultiplier, with wavelength selected with Jobin-Ivon H20 monochromator and Canberra instruments time-to-amplitude converter and multichannel analyser. Alternate measurements (1000 counts per cycle at the maximum) of the pulse profile at $420 \mathrm{~nm}$ and the sample emission were performed until $5 \times 10^{3}$ counts at the maximum were reached. The fluorescence decays were analysed using the method of modulating functions of Striker, with automatic correction for the photomultiplier "wavelength shift" [21].

Time-resolved photoacoustic calorimetry (PAC) measurements were made with a front-face cell using a dielectric mirror [22], that allows for a minimum background and maximum sensitivity of these measurements. Our PAC apparatus and the procedure employed in the measurements was recently described in detail $[14,23]$. In short, the sample and reference solutions, and the solvent, were flown separately with a $1 \mathrm{ml} / \mathrm{min}$ rate (SSI chromatographic pump) through a $0.11 \mathrm{~mm}$ thick cell. They were irradiated at $421 \mathrm{~nm}$ with an unfocused PTI dye laser (model PL202), pumped by a $\mathrm{N}_{2}$ laser (PL2300) working at a frequency of $2 \mathrm{~Hz}$. A small fraction of the laser beam was reflected to a 
photodiode, used to trigger the transient recorder (Tektronix DSA 601, 1 Gs/s). The photoacoustic waves, detected with a $2.25 \mathrm{MHz}$ Panametrics transducer (model 5676) and captured by the transient recorder, were transferred to a PC for data analysis. In a typical PAC experience 100 waves of the sample, reference and pure solvent are recorded and averaged in the same experimental conditions. Four sets of averaged sample, reference and solvent waves are used for the data analysis at a given laser intensity, and four laser intensities are employed in each experiment. The different laser intensities are obtained by interposing neutral density filters with transmissions between $25 \%$ and $100 \%$. All the measurements were made in toluene using either $\mathrm{Mn}$ (III)-5,10,15,20-tetrakisphenylporphyrinate acetate or all trans- $\beta$-carotene as photoacoustic reference.

\subsection{Synthesis}

The synthesis of 2-bromo-5-methoxybenzaldehyde, 2,4-dibromo-5-methoxybenzaldehyde and 2,4,6-tribromo-5-methoxybenzaldehyde followed literature procedures [24]; After recrystallisation in water/ethanol we obtained 2-bromo-5-methoxybenzaldehyde, 2,4-dibromo-5-methoxybenzaldehyde or 2,4,6-tribromo-5-methoxybenzaldehyde with $83 \%, 93 \%$ and $91 \%$ yields, respectively. Characterisations are presented below.

5,10,15,20-Tetrakis(2-bromo-5-methoxyphenyl)porphyrin and 5,10,15,20-tetrakis (2,4-dibromo5-methoxyphenyl)porphyrin were synthesised according to Lindsey procedure [25]. A solution of $1.8 \mathrm{mmol}$ of the corresponding aldehyde and $0.13 \mathrm{ml}$ $(1.8 \mathrm{mmol})$ of pyrrole in $300 \mathrm{ml}$ of distilled $\mathrm{CH}_{2} \mathrm{Cl}_{2}$ was purged with $\mathrm{N}_{2}$ for $15 \mathrm{~min}$, then $0.3 \mathrm{ml}$ of $\mathrm{BF}_{3} \cdot \mathrm{O}(\mathrm{Et})_{2}$ was added at room temperature. The solution was left during $3 \mathrm{~h}$ then neutralised with triethylamine. Then DDQ, $0.8 \mathrm{~g}(3.5 \mathrm{mmol})$ in $40 \mathrm{ml}$ of toluene was added and the mixture is left overnight. The solvent was removed and the residue was chromatographed in alumina $\left(\mathrm{CH}_{2} \mathrm{Cl}_{2}\right.$ /petroleum ether 40-60) giving the porphyrin as a red band. Recrystallisation in $\mathrm{CH}_{2} \mathrm{Cl}_{2}$ /methanol gave an analytical sample.

The other porphyrins were prepared according to a previously described method [26], with the following general procedure. Arylaldehyde (0.4 mmol) was dissolved in a mixture of acetic acid $(140 \mathrm{ml}, 2.45 \mathrm{~mol})$ and nitrobenzene $(70 \mathrm{ml}, 0.68$ $\mathrm{mol})$, and the temperature was raised to $120{ }^{\circ} \mathrm{C}$. Pyrrole $(2.8 \mathrm{ml}, 0.4 \mathrm{mmol})$ was then added. The reaction was carefully followed by UV-Vis until the Soret band intensity reaches its maximum. At this point the solution was cooled to room temperature to give porphyrin crystals, which were filtered off and washed with methanol. The porphyrin was recrystallised with dichloromethane/ methanol. The data for $\mathrm{H}_{2} \mathrm{TPP}, \mathrm{H}_{2} \mathrm{TPPF}_{8}$, $\mathrm{H}_{2} \mathrm{TPPCl}_{4}$ and $\mathrm{H}_{2} \mathrm{TPPCl}_{8}$ characterisation are in close agreement with our previous results [13].

Zinc(II) 5,10,15,20-tetrakis(2-bromo-5-methoxyphenyl)porphyrinate and zinc(II) 5,10,15,20-tetrakis(2,4-dibromo-5-methoxyphenyl)porphyrinate were prepared according to a previous described method [27]. To a solution of $120 \mathrm{mg}$ ( $0.11 \mathrm{mmoles})$ of the corresponding porphyrin in $30 \mathrm{ml}$ of $\mathrm{CHCl}_{3}, 100 \mathrm{mg}$ (0.46 mmoles) of $\mathrm{Zn}(\mathrm{OAc})_{2} \cdot 2 \mathrm{H}_{2} \mathrm{O}$ in $4 \mathrm{ml}$ of methanol was added. The mixture was refluxed for $2 \mathrm{~h}$ to complete metallation. The mixture was diluted with dichloromethane, washed with water, dried over $\mathrm{Na}_{2} \mathrm{SO}_{4}$ and evaporated to dryness. The residue was chromatographed on silica gel $\left(\mathrm{CH}_{2} \mathrm{Cl}_{2} /\right.$ petroleum ether 40-60, 8:2) to give the corresponding zinc complex. Recrystallisation in $\mathrm{CH}_{2} \mathrm{Cl}_{2} /$ methanol gave an analytical sample.

Zinc(II) 5,10,15,20-tetrakis(2,4,6-tribromo5-methoxyphenyl)porphyrinate was synthesised from a solution of $1.75 \mathrm{~g}$ (4.9 mmoles) of 2,4,6tribromo-5-methoxybenzaldehyde and $0.35 \mathrm{ml}(4.9$ mmoles) of pyrrol in $600 \mathrm{ml}$ of distilled $\mathrm{CH}_{2} \mathrm{Cl}_{2}$ previously purged with $\mathrm{N}_{2}$. After $20 \mathrm{~min}, 0.2 \mathrm{ml}$ of $\mathrm{BF}_{3} \cdot \mathrm{O}(\mathrm{Et})_{2}$ was added at room temperature. The solution was left overnight, neutralised with triethylamine and concentrated in vacuum. The residue was dissolved in $20 \mathrm{ml}$ of $\mathrm{CH}_{2} \mathrm{Cl}_{2}$ and $100 \mathrm{ml}$ of acetic acid and $1.0 \mathrm{~g}$ of zinc acetate was added. The mixture was stirred $30 \mathrm{~min}$ at room temperature and then $1 \mathrm{ml}$ of $\mathrm{H}_{2} \mathrm{O}_{2}(50 \%)$ was added. After $2 \mathrm{~h}$ the solvent was evaporated in vacuum. Then, $100 \mathrm{ml}$ of $\mathrm{CH}_{2} \mathrm{Cl}_{2}$ were added to the residue and the mixture was washed successively with water, hydrogen carbonate $(10 \%)$ and water. The solvent was removed in vacuum and the residue 
chromatographed on alumina $\left(\mathrm{CH}_{2} \mathrm{Cl}_{2}\right)$ to give $0.39 \mathrm{~g}$ of the zinc complex of 5,10,15,20-tetrakis(2,4,6-tribromo-5-methoxyphenyl)porphyrin as a red band. Recrystallisation in $\mathrm{CH}_{2} \mathrm{Cl}_{2} / \mathrm{MeOH}$ gave an analytical sample.

$\mathrm{Zn}$ (II) 5,10,15,20-tetrakisphenylporphyrinate, $\mathrm{Zn}$ (II) 5,10,15,20-tetrakis(2,6-halogenophenyl) porphyrinates, Cd(II) 5,10,15,20-tetrakisphenylporphyrinate and $\operatorname{Mg}(\mathrm{II})$ 5,10,15,20-tetrakisphenylporphyrinate were synthesised with slight modifications of Adler's method [28], with the following general procedure. Porphyrin $(0.33$ mmol) was dissolved in $80 \mathrm{ml}$ of dry dimetylformamide and the temperature was raised to $150{ }^{\circ} \mathrm{C}$. Then, acetate salt $(3.3 \mathrm{mmol})$ of the desired metal was added to the reaction mixture. The reaction was monitored by UV-Vis spectroscopy until the degeneracy of the $\mathrm{Q}$ bands was observed. After work-up, the metal complexes were obtained by several recrystallisations with dichloromethane/ methanol 1:5 giving the metal complexes. The characterisations of $\mathrm{ZnTPP}, \mathrm{ZnTPPF}_{8}$ and $\mathrm{ZnTPPCl}_{8}$ were in agreement with our previous results [13]. Yields and characterisation of CdTPP and MgTPP are described below.

\subsection{Characterisation}

2-Bromo-5-methoxybenzaldehyde. Yield: 83\%; mp 74-75 ${ }^{\circ} \mathrm{C}$ (lit. mp $76{ }^{\circ} \mathrm{C}$ ) [29]; ${ }^{1} \mathrm{H}$ NMR $\left(\mathrm{CDCl}_{3}\right): \delta(\mathrm{ppm})=10.11(\mathrm{~s}, 1 \mathrm{H}, \mathrm{CHO}), 7.36(\mathrm{~d}$, $1 \mathrm{H}, J=8.8 \mathrm{~Hz}, \operatorname{ArH}), 7.22(\mathrm{~d}, 1 \mathrm{H}, J=3.2 \mathrm{~Hz}$, ArH), $6.88(\mathrm{dd}, 1 \mathrm{H}, J=8.8 \mathrm{~Hz}, J=3.2 \mathrm{~Hz}, \mathrm{ArH})$, $3.74\left(\mathrm{~s}, 3 \mathrm{H}, \mathrm{OCH}_{3}\right)$.

2,4-Dibromo-5-methoxybenzaldehyde. Yield: 93\%; mp 111-112 ${ }^{\circ} \mathrm{C}$ (lit. mp $110{ }^{\circ} \mathrm{C}$ ) [29]; ${ }^{1} \mathrm{H}$ NMR $\left(\mathrm{CDCl}_{3}\right): \delta(\mathrm{ppm})=10.24(\mathrm{~s}, 1 \mathrm{H}, \mathrm{CHO}), 7.83(\mathrm{~s}$, $1 \mathrm{H}, \mathrm{ArH}), 7.39$ (s, 1H, ArH), 3.94 (s, 3H, $\left.\mathrm{OCH}_{3}\right)$.

2,4,6-Tribromo-5-methoxybenzaldehyde. Yield: 91\%; mp 111-112 ${ }^{\circ} \mathrm{C}$ (lit. mp $113{ }^{\circ} \mathrm{C}$ ) [29]; ${ }^{1} \mathrm{H}$ NMR $\left(\mathrm{CDCl}_{3}\right): \delta(\mathrm{ppm})=10.15(\mathrm{~s}, 1 \mathrm{H}, \mathrm{CHO})$, 7.89 (s, 1H, CH-Ar), 3.91 (s, 3H, Me); ${ }^{13} \mathrm{C} \delta$ (ppm): 190.4 (CO), 154.7 (COMe), $137.3(\mathrm{CH})$, $133.5(\mathrm{C}-\mathrm{CO}), 123.2(\mathrm{CBr}), 121.3(\mathrm{CBr}), 118.9$ $(\mathrm{CBr}), 60.6(\mathrm{Me})$.

5,10,15,20-Tetrakis(2-bromo-5-methoxyphenyl) porphyrin. Yield: $22 \% ; \mathrm{C}_{48} \mathrm{H}_{34} \mathrm{~N}_{4} \mathrm{O}_{4} \mathrm{Br}_{4}$, Found: C, 55.2; H, 3.4; N, 5.3. Calcd.: C, 54.9\%; H, 3.3\%; N,
$5.3 \% ;{ }^{1} \mathrm{H}$ NMR $\left(\mathrm{CDCl}_{3}\right): \delta(\mathrm{ppm})=8.9-8.7(\mathrm{~m}$, $8 \mathrm{H}, \beta-\mathrm{H}), 7.9-7.3(\mathrm{~m}, 12 \mathrm{H}, \mathrm{Ar}), 4.2-3.9(\mathrm{~m}, 12 \mathrm{H}$, $\mathrm{Me}),-2.6-2.7$ (m, 2H, NH); $\mathrm{Ms}(\mathrm{FAB}) m / z=1050$ (molecular ion); V/UV $\left(\mathrm{CH}_{2} \mathrm{Cl}_{2}\right): \lambda_{\max }(\log \varepsilon$ $\left.\left(\mathrm{M}^{-1} \mathrm{~cm}^{-1}\right)\right)=419$ (5.52), 453 (4.1), 513 (4.29), 546 (3.66), 588 (3.79), 644 (3.32).

5,10,15,20-Tetrakis(2,4-dibromo-5-methoxyphenyl)porphyrin. Yield: $18 \% ; \mathrm{C}_{48} \mathrm{H}_{30} \mathrm{~N}_{4} \mathrm{O}_{4} \mathrm{Br}_{8} \cdot \mathrm{H}_{2} \mathrm{O}$ : Found: C, 41.3; H, 2.8; N, 3.6. Calcd.: C, 41.7\%; $\mathrm{H}, 2.3 \%$; N, 4.0\%; ${ }^{1} \mathrm{H}$ NMR $\left(\mathrm{CDCl}_{3}\right): \delta(\mathrm{ppm})=$ 8.75 (s (large), $8 \mathrm{H}, \beta-\mathrm{H}), 8.20-8.17$ (m, $4 \mathrm{H}, \mathrm{Ar}$ ), 7.73-7.61 (m, 4H, Ar), 3.95-3.88 (m, 12H, Me), -2.72 (s, 2H, NH); Ms(FAB) $m / z=1366$ (molecular ion); V/UV $\left(\mathrm{CH}_{2} \mathrm{Cl}_{2}\right): \lambda_{\max }(\log \varepsilon$ $\left.\left(\mathrm{M}^{-1} \mathrm{~cm}^{-1}\right)\right)=419$ (5.52), 513 (4.43), 545 (sh), 587 (4.11).

Zinc(II) 5,10,15,20-tetrakis(2-bromo-5-methoxyphenyl)porphyrinate $\left(\mathrm{ZnTPPBr}_{4}\right)$. Yield, 94\%; $\mathrm{C}_{48} \mathrm{H}_{32} \mathrm{~N}_{4} \mathrm{O}_{4} \mathrm{Br}_{4} \mathrm{Zn}$ Found: C, 51.5; H, 3.0; N, 4.8. Calcd.: C, 51.8\%; H, 2.9\%; N, 5.0\%; ${ }^{1}$ H NMR (300 $\left.\mathrm{MHz} ; \mathrm{CDCl}_{3}\right) \delta(\mathrm{ppm}), 8.82-8.77(\mathrm{~m}, 8 \mathrm{H}, \beta-\mathrm{H})$, 7.85-7.59 (m, 8H, Ar), 7.21-7.15 (m, 4H, Ar), 3.88-3.77 (m, 12H, Me); V/UV $\left(\mathrm{CH}_{2} \mathrm{Cl}_{2}\right): \lambda_{\max }(\mathrm{log}$ $\left.\varepsilon\left(\mathrm{M}^{-1} \mathrm{~cm}^{-1}\right)\right)=420$ (5.62), 548 (4.37); $\mathrm{Ms}(\mathrm{FAB})$ : $m / z=1114$ (molecular ion).

Zinc(II) 5,10,15,20-tetrakis(2,4-dibromo-5-methoxyphenyl)porphyrinate $\left(\mathrm{ZnTPPBr}_{4}\left(\mathrm{Br}_{4}\right)\right)$. Yield: $96 \% ; \mathrm{C}_{48} \mathrm{H}_{28} \mathrm{~N}_{4} \mathrm{O}_{4} \mathrm{Br}_{8} \mathrm{Zn} \cdot \mathrm{MeOH}: \mathrm{C}, 40.7 ; \mathrm{H}, 2.9$; N, 3.1. Calcd.: C, $40.3 \% ; \mathrm{H}, 2.2 \% ; \mathrm{N}, 3.8 \% ;{ }^{1} \mathrm{H}$ NMR (300 MHz, $\left.\mathrm{CDCl}_{3}\right): \delta(\mathrm{ppm})=8.84-8.79(\mathrm{~m}$, $8 \mathrm{H}, \beta-\mathrm{H}), 8.20-8.14(\mathrm{~m}, 4 \mathrm{H}, \mathrm{Ar}), 7.75-7.59(\mathrm{~m}$, $4 \mathrm{H}, \mathrm{Ar}), 3.94-3.86$ (m, 12H, Me); $\mathrm{Ms}(\mathrm{FAB})$ : $m / z=1430$ (molecular ion); V/UV $\left(\mathrm{CH}_{2} \mathrm{Cl}_{2}\right): \lambda_{\max }$ $\left(\log \varepsilon\left(\mathrm{M}^{-1} \mathrm{~cm}^{-1}\right)\right)=422$ (5.61), 549 (4.32).

Zinc(II) 5,10,15,20-tetrakis(2,4,6-tribromo-5-methoxyphenyl)porphyrinate $\left(\mathrm{ZnTPPBr}_{8}\left(\mathrm{Br}_{4}\right)\right)$. Yield: $18 \% ; \mathrm{C}_{48} \mathrm{H}_{24} \mathrm{~N}_{4} \mathrm{O}_{4} \mathrm{Br}_{12} \mathrm{Zn} \cdot \mathrm{MeOH}$ : Found: C, 34.0; H, 1.71; N, 3.29. Calcd.: C, 33.1\%; H, 1.59\%; N, $3.15 \% ;{ }^{1} \mathrm{H}$ NMR $\left(300 \mathrm{MHz} ; \mathrm{CDCl}_{3}\right): \delta(\mathrm{ppm})=$ $8.72(\mathrm{~s}, 8 \mathrm{H}, \beta-\mathrm{H}), 8.25$ (s, 4H, Ar), $4.11(\mathrm{~s}, 12 \mathrm{H}$, $\mathrm{Me}$ ); $\mathrm{Ms}(\mathrm{FAB}) \mathrm{m} / z=1743$ (molecular ion); V/UV $\left(\mathrm{CH}_{2} \mathrm{Cl}_{2}\right): \lambda_{\max }\left(\log \varepsilon\left(\mathrm{M}^{-1} \mathrm{~cm}^{-1}\right)\right)=426$ (5.52), 554 (4.49).

Cadmium(II) 5,10,15,20-tetrakisphenylporphyrinate (CdTPP). Yield: $90 \% ; \quad \mathrm{C}_{44} \mathrm{H}_{28} \mathrm{~N}_{4} \mathrm{Cd}$. $7 \mathrm{CH}_{3} \mathrm{OH}$, Found: C, 65.48; H, 5.43; N. 5.91 Calcd.: C, $64.5 \%$; H, 5.9\%; N, 5.9\%; ${ }^{1}$ H NMR (300 $\left.\mathrm{MHz} ; \mathrm{CDCl}_{3}\right): \delta(\mathrm{ppm})=8.84(\mathrm{~s}, 8 \mathrm{H}, \beta-\mathrm{H}), 8.23$ 
(m, 8H, Ar), $7.75(\mathrm{~m}, 12 \mathrm{H}, \mathrm{Ar})$; $\mathrm{Ms}(\mathrm{FAB})$ : $m / z=725$ (molecular ion).

Magnesium(II) 5,10,15,20-tetrakisphenylporphyrinate (MgTPP). Yield: $80 \% ; \mathrm{C}_{44} \mathrm{H}_{28} \mathrm{~N}_{4} \mathrm{Mg}$. $3 \mathrm{H}_{2} \mathrm{O}$ Found: $\mathrm{C}, 76.84 ; \mathrm{H}, 4.85$; N, 9.76 Calcd.: $\mathrm{C}$, $76.52 \%$; H, 4.92\%; N, 8.12\%; ${ }^{1} \mathrm{H}$ NMR $(300 \mathrm{MHz}$; $\left.\mathrm{CDCl}_{3}\right): \delta(\mathrm{ppm})=8.83(\mathrm{~s}, 8 \mathrm{H}, \beta-\mathrm{H}), 8.20(\mathrm{~d}, 8 \mathrm{H}$, Ar), 7.70 (m, 12H, Ar); Ms (FAB): $m / z=636$ (molecular ion); V/UV (toluene): $\lambda_{\max }(\log \varepsilon$ $\left.\left(\mathrm{M}^{-1} \mathrm{~cm}^{-1}\right)\right)=426$ (5.52), 564 (4.17), 604 (3.94).

\section{Results}

Some photophysical properties of porphyrins addressed in this work have already been measured in other laboratories [1,17,30,31]. We did not measure the fluorescence lifetimes of the species with $\Phi_{\mathrm{F}} \leqslant 0.005$ due to sensitivity limitations at the wavelengths where the porphyrins emit. Lifetimes shorter than 200 ps are beyond the time resolution of our apparatus [32]. The lifetimes of the brominated porphyrins were measured at Centro de Química-Física Molecular (Instituto Superior Técnico, Lisboa). Thus, Table 1 collects the fluorescence and triplet yields, singlet $S_{1}$ and triplet $T_{1}$ lifetimes and energies, and $\mathrm{S}_{1} \rightarrow \mathrm{T}_{1}$ and $\mathrm{T}_{1} \rightarrow \mathrm{S}_{0}$ intersystem crossing rate constants measured in our laboratory for all the porphyrins synthesised in this work, except for $\Phi_{\mathrm{F}}$ and $\tau_{\mathrm{F}}$ of CdTPP, $\mathrm{H}_{2} \mathrm{TPPCl}_{8}$ and $\mathrm{ZnTPPCl}_{8}$. For the reasons mentioned above, the singlet lifetimes of these porphyrins were taken from the literature.

With the exception of MgTPP and $\mathrm{H}_{2} \mathrm{TPPF}_{8}$, our measurements are in good agreement with the available data. We found that our sample of MgTPP has a significantly larger fluorescence quantum yield than the literature value, $\Phi_{\mathrm{F}}=0.29 \pm 0.02$ vs 0.15 [18] or 0.13 [33], but a comparable lifetime, 7.6 vs 8.9 ns [1]. The reasons for this discrepancy are discussed below. The fluorescence lifetime of our $\mathrm{H}_{2} \mathrm{TPPF}_{8}$ sample is appreciable smaller than that reported by Yang et al. [1] 8.5 vs 15.1 , although we agree on the value of $\Phi_{\mathrm{F}}$. Fig. 1 shows the fluorescence decay of $\mathrm{H}_{2} \mathrm{TPPF}_{8}$ obtained with our single photon counting apparatus. The monoexponential fit is of ex- cellent quality and we believe that it is a better description of the lifetime of this species. We exclude the possibility of quenching by an impurity because this would lead to a decrease in $\Phi_{\mathrm{F}}$.

\section{Discussion}

\subsection{Experimental quantum yields}

The discrepancy between the $\Phi_{\mathrm{F}}$ value of MgTPP measured in this work and the values found in the literature deserves a detailed discussion, because MgTPP is a popular compound and has been used as fluorescence [1]. We synthesised two independent batches of MgTPP and for both of them obtained crystals with excellent elemental analysis (considering the presence of hydration water molecules) and NMR. Two co-authors of this work independently obtained $\Phi_{\mathrm{F}}=0.29 \pm 0.02$ using fresh $\mathrm{N}_{2}$-saturated toluene solutions and taking TPP as the fluorescence standard. In order to explain the literature value, $\Phi_{\mathrm{F}}=0.15$, we repeated the quantum yield measurements of the same MgTPP solution in toluene at different times after its preparation. The quantum yields dropped rapidly with time, as shown in Fig. 2, reaching the literature value in less than $24 \mathrm{~h}$. The aged MgTPP solutions have a new emission at $717 \mathrm{~nm}$. The fluorescence excitation spectrum of this emission has a maximum at $418 \mathrm{~nm}$, that is, at the same place as the Soret band of TPP. The fluorescence excitation of the fresh MgTPP solution does not show this maximum, on the contrary, its maximum is at $426 \mathrm{~nm}$, just like its absorption spectrum. We conclude that MgTPP is prone to loose its metal in solution and yields a mixture of free-base and metallated TPP. It should not be used as fluorescence standard. We emphasise that we were particularly careful in neutralising our solvent after its purification and did not find evidence for the characteristic absorption and emission spectra of protonated TPP in solution. Thus, de-metallation may occur even in the absence of acids.

Triplet quantum yields were determined from the triplet energy $\left(E_{\mathrm{T}}\right)$ given by phosphorescence, and from fraction of energy released in the formation of the triplet state given by $\operatorname{PAC}\left(\phi_{1}\right)$ [13] 
Table 1

Photophysical properties of porphyrins. Single state properties at room temperature in benzene, and triplet state at $77 \mathrm{~K}$ toluene matrix

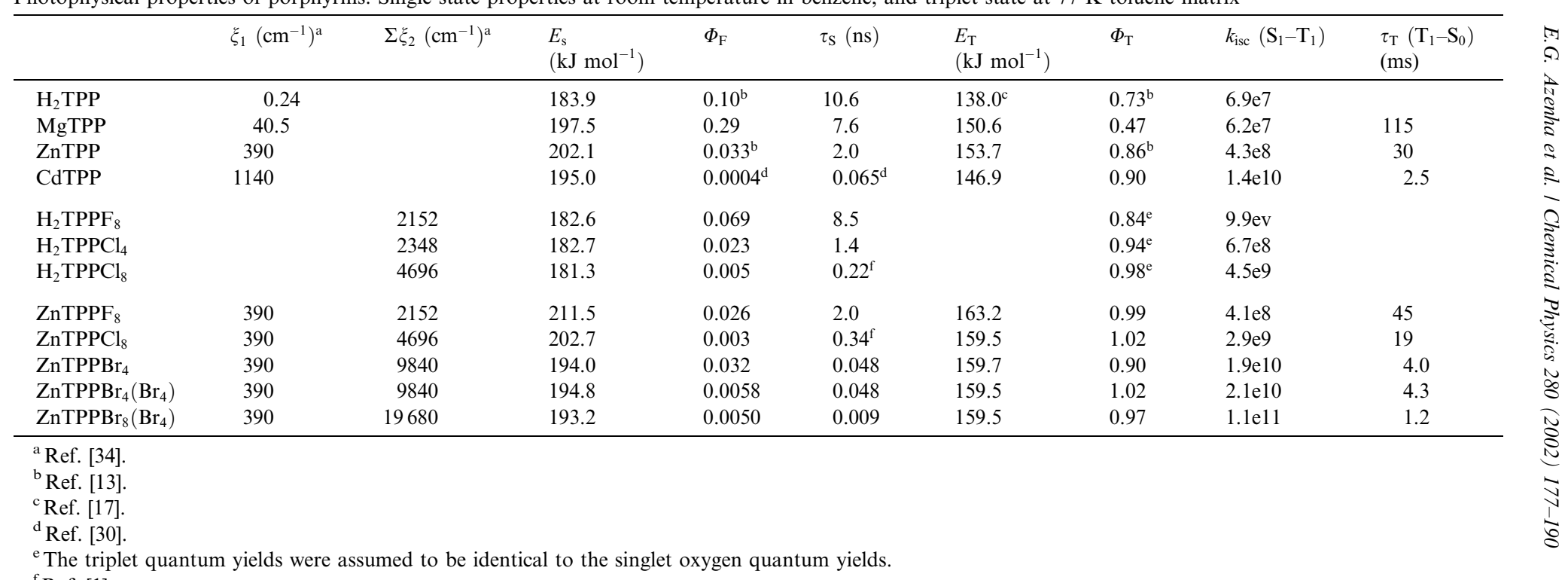

${ }^{\mathrm{f}}$ Ref. [1]. 


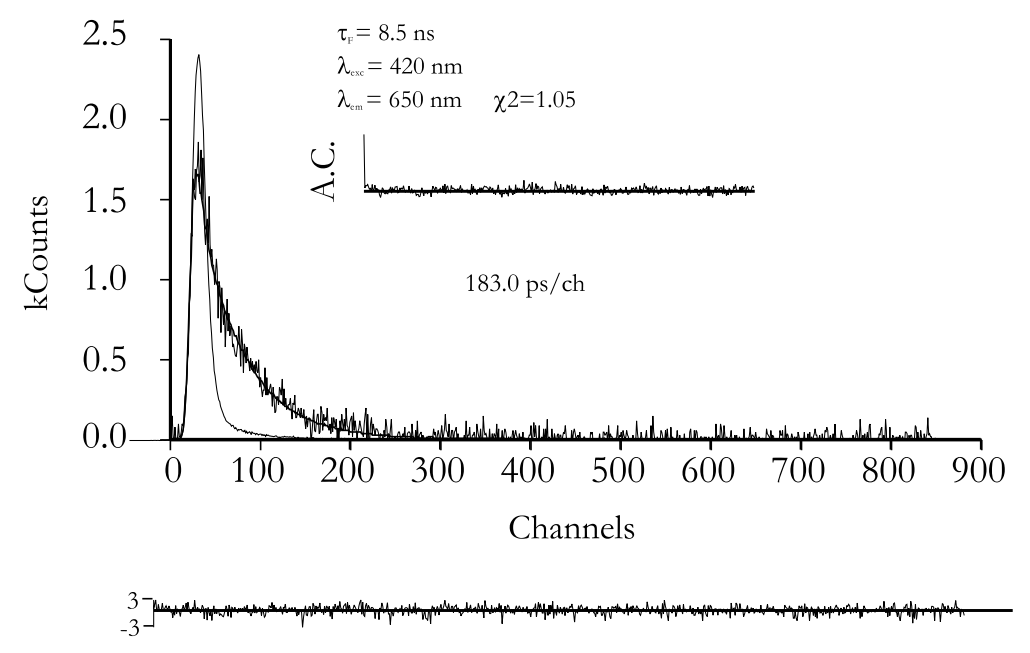

Weighted Residuals

Fig. 1. Fluorescence decay and pulse instrumental response, with $\lambda_{\mathrm{exc}}=420 \mathrm{~nm}$ and $\lambda_{\mathrm{em}}=650 \mathrm{~nm}$, for $\mathrm{H}_{2} \mathrm{TPPF}_{8}$ in toluene. The quality of the fit can be judged from the chi-square autocorrelation function, and weighted residuals.

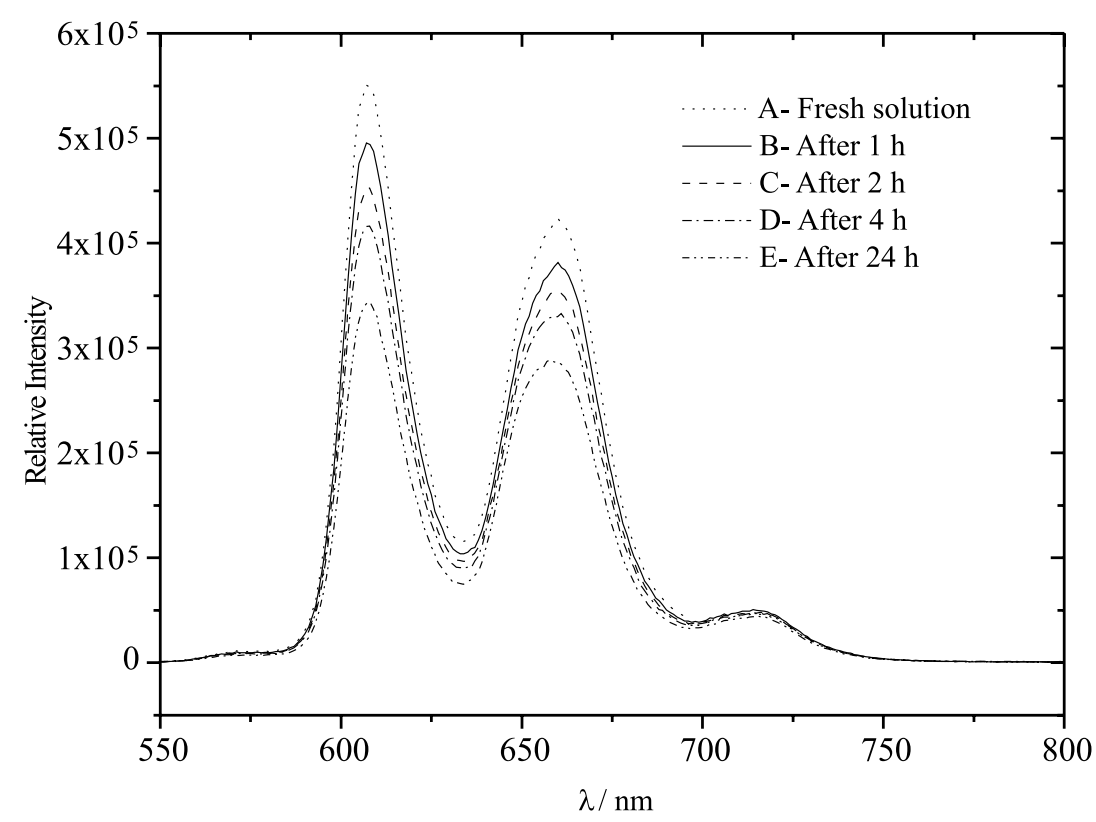

Fig. 2. Decrease of the fluorescence quantum yield $\left(\Phi_{\mathrm{F}}\right)$ of MgTPP with time in toluene solution. (a) Fresh solution, $\Phi_{\mathrm{F}}=0.27 ;$ (b) $1 \mathrm{~h}$ later, $\Phi_{\mathrm{F}}=0.22$; (c) $2 \mathrm{~h}$ later, $\Phi_{\mathrm{F}}=0.20$; (d) $4 \mathrm{~h}$ later, $\Phi_{\mathrm{F}}=0.19$; (e) $24 \mathrm{~h}$ later, $\Phi_{\mathrm{F}}=0.15$. The solutions were kept at room temperature and exposed to air and ambient light between measurements. Before each fluorescence measurement, the sample used for analysis was saturated with $\mathrm{N}_{2}$. TPP was used as fluorescence standard. 
$\Phi_{\mathrm{T}}=\frac{\left(1-\phi_{1}\right) E_{h v}-\Phi_{\mathrm{F}} E_{h v \max }}{E_{\mathrm{T}}}$,

where $E_{\mathrm{h} v}$ is the energy of the incident light and $E_{\mathrm{h} v \max }$ is the energy at the maximum fluorescence intensity. We were unable to detect the phosphorescence of free-base porphyrins. Given their relatively long lifetimes, we assumed that their $\Phi_{\mathrm{T}}$ were identical to the corresponding singlet oxygen quantum yields in aerated solution, given by [14]

$\Phi_{\Delta}=\frac{\Phi_{\mathrm{T}} E_{\mathrm{T}}-E_{h v} \phi_{2}}{E_{\Delta}}$,

where $E_{\Delta}$ is the singlet oxygen energy $(94.1 \mathrm{~kJ}$ $\left.\mathrm{mol}^{-1}\right), \phi_{2}$ is the fraction of energy released in the formation of singlet oxygen and $\Phi_{\mathrm{T}} E_{\mathrm{T}}$ was obtained from the first fraction of energy released, according to Eq. (1).

\subsection{Radiationless transitions}

The main goal of this work is to rationalise the intersystems crossing rates of porphyrins because they control triplet quantum yields and lifetimes. In the set of diamagnetic porphyrins selected for this study, we can expect to correlate the variations observed in $k_{\text {isc }}$ and $\tau_{\mathrm{T}}$ with the presence of heavy atoms in the structure of the porphyrins.

Heavy-atom effects in the transitions between singlet and triplet states are usually interpreted in terms of the coupling of the relativistic magnetic field of the motion of a nuclear charge around an electron considered to be fixed, and the magnetic field of the electron-spin motion (spin-orbit coupling). Those effects are proportional to the (square of the) spin-orbit coupling factor, $\xi$, of an atom with a high atomic number, $Z$, that outweighs all the other atoms $\left(\xi \approx Z^{4}\right)$ [16]. Additionally, just like other radiationless transitions in the weak-coupling limit [35], intersystems crossing rates present an inverse relationship with the difference in energy, $\Delta E_{\mathrm{S}-\mathrm{T}}$, of the singlet and triplet states and are proportional to the relative number of vibrational modes, $\eta$, involved in the transition [36]. Thus, even if the nature of the excited states is not affected by the heavy-atom substitution and symmetry characteristics do not reduce heavyatom/porphyrin orbital overlap, intersystems crossing rates are a function of $\xi^{2}, \Delta E_{\mathrm{S}-\mathrm{T}}$ and $\eta$.
Within the Born-Oppenheimer approximation, the calculation of the radiationless transition rate between the initial state $a$ and the final state $b$ of large molecules is usually expressed in terms of the product between an electronic and a nuclear factor [37]

$\operatorname{rate}(a \rightarrow b)=\frac{2 \pi}{\hbar}\left|H_{a b}\right|^{2} \mathrm{FCWD}$,

where $H_{a b}$ is the matrix element of the quantummechanical Hamiltonian which governs the rate of the transition, and FCWD is the Franck-Condon factor, that is the number of substrates qualifying as $b$ per unit interval of energy. The interpretation of internal heavy-atom effects in a series of compounds usually focus on the expected dependence of $H_{a b}$ on $\xi$, and employs constant or empirical values for FCWD $[38,39]$. This approach is restricted to families of closely related molecules where only one parameter is changing while the others remain constant. Systems involving multiple substitutions at different sites of the molecules concomitant with variable energy gaps require a model that can simultaneously account for all these factors.

Nearly 30 years ago, Formosinho showed that the rates of radiationless transitions could be interpreted as quantum mechanical tunnelling from the bottom of the higher energy potential energy surface to an isothermic position on the lower energy surface, Fig. 3. Under the WKB approximation $[20,40]$, the Tunnel Effect Theory (TET) expresses the tunnelling rate as

$k=\chi v \exp \left[-\frac{2 \pi}{h} \sqrt{2 \mu\left(D-E_{v}\right)} \frac{\Delta x}{2 \eta}\right]$,

where $\chi$ is the electronic factor, $v$ is the frequency of the vibrational mode $\left(v_{\mathrm{CH}}=3000 \mathrm{~cm}^{-1}\right.$ and $\left.v_{\mathrm{CC}}=1050 \mathrm{~cm}^{-1}\right), \mu$ its reduced mass $\left(\mu_{\mathrm{CH}}=0.923\right.$ and $\left(\mu_{\mathrm{CC}}=6\right), D-E_{\mathrm{v}}$ is the barrier height, $\Delta x$ is the barrier width defined in Fig. 3, and $\eta$ is the relative number of atoms. The exponential part of the equation represents the Franck-Condon factor between a vibrational wavefunction in the nonadiabatic region of the initial electronic state and a vibrational function in the final state, taken as a $\delta$ function at the classical turning point of vibration. Jortner and Ulstrup [41] have shown that the 


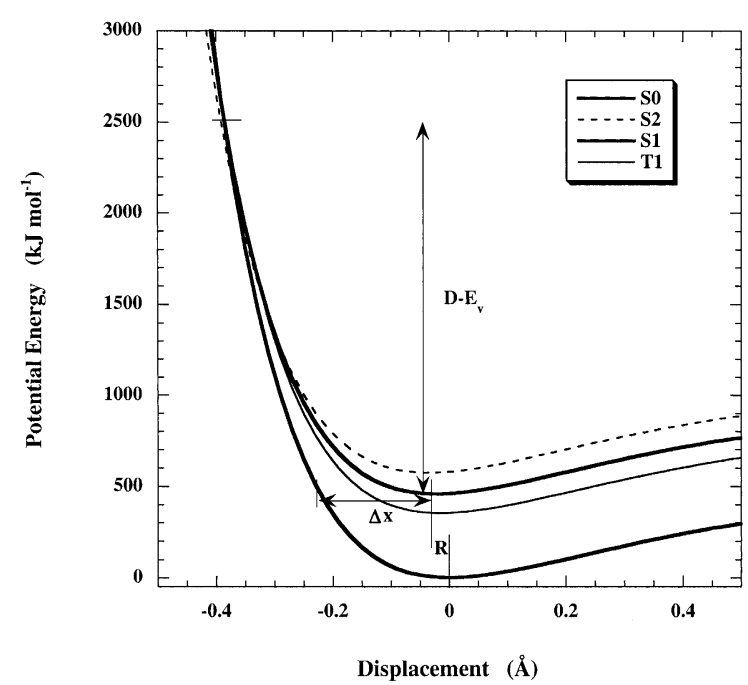

Fig. 3. Anharmonic potential energy curve of the generalised $\mathrm{CH}$ vibrational modes; $\Delta x$ is the tunnelling barrier width on the attractive side.

Franck-Condon vibrational overlap factors of some radiationless transitions can be recast is a form that is practically identical with Eq. (4). The importance of $\mathrm{CH}$ and $\mathrm{CC}$ stretching modes on radiationless conversions depends on the number of hydrogen $\left(n_{\mathrm{H}}\right)$, carbon $\left(n_{\mathrm{C}}\right)$ and other atoms $\left(n_{\mathrm{X}}\right)$. The role of the relative number of atoms

$$
\begin{aligned}
& \eta_{\mathrm{H}}=\frac{n_{\mathrm{H}}}{n_{\mathrm{H}}+n_{\mathrm{C}}+n_{\mathrm{X}}}, \\
& \eta_{\mathrm{C}}=\frac{n_{\mathrm{C}}}{n_{\mathrm{H}}+n_{\mathrm{C}}+n_{\mathrm{X}}}
\end{aligned}
$$

has been shown empirically by Siebrand [42].

This method of calculation of the FranckCondon factor requires the knowledge of the nuclear displacement between the initial and final electronic states, and a function to describe the dependence of the energy on the nuclear co-ordinates. McCoy and Ross [43] showed that the electronic transitions in polycyclic aromatic hydrocarbons (PAH) can be expressed in terms of a bond-length displacement co-ordinate $R$,

$R=\left(\sum_{j} \Delta r_{j}^{2}\right)^{1 / 2}$,

where $\Delta r_{j}$ denotes the change in the length of the jth bond. Each $\mathrm{CH}$ bond of benzene contracts by
$0.009 \AA$ upon electronic excitation from the $\mathrm{S}_{0}$ to the $\mathrm{S}_{1}$ state [44-46]. This contraction of the $\mathrm{CH}$ bonds directs tunnelling to the repulsive side of the potential energy curves.

A simple way to describe the dependence of the energy on the nuclear co-ordinates is to employ Morse curves

$V(l)=D_{\mathrm{e}}\left\{1-\exp \left[-\beta\left(l-l_{\mathrm{eq}}\right)\right]\right\}^{2}$,

where $D_{\mathrm{e}}$ is the depth of the potential well, $l_{\text {eq }}$ is the equilibrium bond length and the Morse parameter $\beta$ is related to the anharmonicity of the oscillator. The Morse curve of a $\mathrm{CH}$ bond in benzene is given by $D_{\mathrm{e}, \mathrm{CH}}=478.2 \mathrm{~kJ} \mathrm{~mol}^{-1}, \beta_{\mathrm{CH}}=$ $1.972 \AA^{-1}$ and $l_{\text {eq,CH }}=1.080 \AA$ [47]. That of a $\mathrm{C}\left(\mathrm{sp}^{2}\right)-\mathrm{C}\left(\mathrm{sp}^{3}\right)$ bond can be built from its dissociation energy $\left(D_{0}=368 \mathrm{~kJ} \mathrm{~mol}^{-1}\right)$, vibrational frequency $\left(v_{\mathrm{CC}}=1050 \mathrm{~cm}^{-1}\right)$ [47], bond length, $l_{\text {eq, CC }}=1.505 \AA$ and harmonic force constant, $f_{\mathrm{CC}}=2.89 \times 10^{3} \mathrm{~kJ} \mathrm{~mol}^{-1} \AA^{-2}$ [48], using the relation

$f=2 D_{\mathrm{e}} \beta^{2}$.

We obtain $D_{\mathrm{e}, \mathrm{CC}}=374.3 \mathrm{~kJ} \mathrm{~mol}^{-1}$ and $\beta_{\mathrm{CC}}=$ $1.965 \AA^{-1}$ for the Morse curve of a $\mathrm{C}\left(\mathrm{sp}^{2}\right)-\mathrm{C}\left(\mathrm{sp}^{3}\right)$ bond.

The Morse curves obtained with these parameters describe the energy variation associated with the nuclear distortion of one oscillator, but the transition involves all the promoting modes of a certain type, $\mathrm{CH}$ or $\mathrm{CC}$. It is well recognised that the role played by $\mathrm{CH}$ stretching vibrations in radiationless transitions of aromatic hydrocarbons is better described in terms of local rather than normal modes [36]. A treatment of local modes as independent oscillators showed that a generalised $\mathrm{CH}$ vibration could be expressed by a force constant $\sqrt{ }\left(n_{\mathrm{H}}\right) f_{\mathrm{CH}}[20,40,49]$. Given the relation expressed by Eq. (8), we chose to express the Morse parameters of generalised $\mathrm{CH}$ and $\mathrm{CC}$ vibrations by

$$
\begin{aligned}
& \beta(\mathrm{CH})=\sqrt[4]{n_{\mathrm{H}}} \beta_{\mathrm{CH}}, \\
& \beta(\mathrm{CC})=\sqrt[4]{n_{\mathrm{C}}} \beta_{\mathrm{CC}} .
\end{aligned}
$$

The contraction of the $\mathrm{CH}$ modes plays a dominant role in the radiationless transitions of benzene given their low reduced mass and thin barrier. For example, the barrier width $\Delta x$ for the 
$\mathrm{S}_{1} \rightarrow \mathrm{S}_{0}$ internal conversion in benzene is the difference between the generalised bond contraction of the $\mathrm{S}_{0}$ state at the $\mathrm{S}_{1}$-state energy $\left(E_{\mathrm{S} 1}=459\right.$ $\left.\mathrm{kJ} \mathrm{mol}^{-1}\right)$, and the bond-length displacement between the two curves $(R=0.022 \AA), \Delta x=0.199 \AA$. The crossing between the Morse curves of the $\mathrm{S}_{0}$ and $\mathrm{S}_{1}$ state gives the barrier height $D-E_{\mathrm{v}}=$ $2.088 \times 10^{3} \mathrm{~kJ} \mathrm{~mol}^{-1}$. The curves represented in Fig. 3 were calculated with the data pertaining to benzene and give a Franck-Condon factor of $3.5 \times 10^{-9}$. The electronic factor can be calculated as electron tunnelling through a triangular [50], or, more exactly, a rectangular barrier [51] with width $\Delta x$ and height $I_{\mathrm{P}}-E_{\mathrm{S} 1}$, where $I_{\mathrm{P}}=9.25 \mathrm{eV}$ is the ionisation potential of benzene. In the case of a triangular barrier we obtain $\chi=0.7$ and in the case of a rectangular barrier we have $\chi=0.5$, this gives an effective transition frequency $v \chi=5 \times 10^{13}$ and a nuclear tunnelling rate of $k_{\mathrm{TET}}=1.7 \times 10^{5} \mathrm{~s}^{-1}$. According to Birks [52], the experimental rate is $k_{\exp }=4 \times 10^{4} \mathrm{~s}^{-1}$. We obtain the internal conversion rate in perdeuterated benzene replacing $\mu_{\mathrm{CH}}$ by $\mu_{\mathrm{CD}}$ and $v_{\mathrm{CH}}$ by $v_{\mathrm{CD}}$. We estimate $1 \times 10^{2} \mathrm{~s}^{-1}$ and Birks reports $3 \times 10^{2} \mathrm{~s}^{-1}$. The calculation of the $\mathrm{S}_{1} \rightarrow \mathrm{S}_{0}$ internal conversion rate in benzene does not involve the fitting of any parameters, although we recognise that Eq. (9) involves some empiricism.

The analogous $\mathrm{S}_{2} \rightarrow \mathrm{S}_{1}$ rate requires the $\mathrm{CH}$ bond length changes from the $S_{1}$ to the $S_{2}$ states. This is not experimentally known, although it is reasonable to expect that it should be smaller than for the $S_{1} \rightarrow S_{0}$ transition. We reproduce the experimental $S_{2} \rightarrow S_{1}$ internal conversion rate in benzene, $k=4 \times 10^{10} \mathrm{~s}^{-1}$ [52], with $\Delta r=0.005 \AA$. The $\mathrm{T}_{1} \rightarrow \mathrm{S}_{0}$ intersystem crossing has a nonadiabatic factor of $\chi=10^{-6}$ [53]. With this $\chi$ and $\Delta r=0.006 \AA$ we reproduce the experimental rate of $0.03 \mathrm{~s}^{-1}$ [52]. Given that $\Delta r=0.009 \AA$ for the $\mathrm{S}_{1} \rightarrow \mathrm{S}_{0}$ transition and $\Delta r=0.006 \AA$ for the $\mathrm{T}_{1} \rightarrow \mathrm{S}_{0}$ transition, we must have $\Delta r=0.003 \AA$ for the $\mathrm{S}_{1} \rightarrow \mathrm{T}_{1}$ transition. The experimental $\mathrm{S}_{1} \rightarrow \mathrm{T}_{1}$ intersystem-crossing rate, $k=8.8 \times 10^{6} \mathrm{~s}^{-1}$ [52], is reproduced with $\chi=2 \times 10^{-3}$. The relative variations in $\Delta r$ and in $\chi$ among the four electronic states meet our expectations and are a good ground to explore radiationless transitions in other PAH.
It is likely that larger PAH have smaller changes in $R$ than benzene but, following Eq. (9), this is compensated by a larger $\beta(\mathrm{CH})$. We avoid speculating about the value of $R$ and the role of $\beta$, and employ the parameters of benzene for all the calculations with PAH. Fig. 4 compares the results of our calculations for a selection of PAH with the experimental rates compiled by Birks [52]. The agreement between calculated and experimental radiationless transition rates is quite remarkable, especially because our selection of data includes a large range of rates (14 orders of magnitude), energy gaps $\left(33-459 \mathrm{~kJ} \mathrm{~mol}^{-1}\right)$ and relative number of atoms $\left(0.333<\eta_{\mathrm{H}}<0.5\right)$. This selection comprises molecules such as benzene, naphthalene, phenanthrene, anthracene, pyrene, coronene, tetracene and azulene.

The internal conversion rate of $\mathrm{H}_{2} \mathrm{TPP}, k_{\mathrm{ic}}=$ $1.6 \times 10^{7} \mathrm{~s}^{-1}$, can be estimated from the experimental data in Table 1 . The tunnelling rates were evaluated with $n_{\mathrm{H}}=10, n_{\mathrm{C}}=4$ and $n_{\mathrm{X}}=24$, that is, only the $\mathrm{C}$ atom of each phenyl group bonded to the meso site was involved in a local mode and included in the calculation of the $\mathrm{CC}$ tunnelling rate. We calculate a rate of $1.4 \times 10^{6} \mathrm{~s}^{-1}$ using the

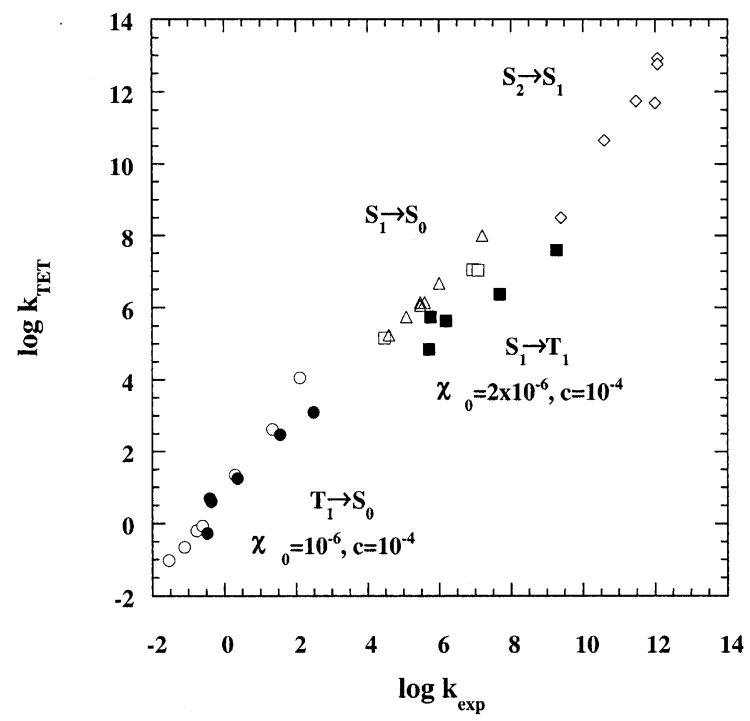

Fig. 4. Correlation between experimental and calculated radiationless transition rates in $\mathrm{PAH}$. The transitions are as follows: $\mathrm{T}_{1} \rightarrow \mathrm{S}_{0}$ represented as circles, $\mathrm{S}_{1} \rightarrow \mathrm{S}_{0}$ as triangles, $\mathrm{S}_{1} \rightarrow \mathrm{T}_{1}$ as squares and $S_{2} \rightarrow S_{2}$ as lozenges. The filled symbols refer to halogenated naphthalenes. 
benzene curves and $1.2 \times 10^{10} \mathrm{~s}^{-1}$ using the $n_{\mathrm{H}}$ factor in $R$ and $\beta$. The actual curves for $\mathrm{H}_{2}$ TPP are somewhat in between these limiting approximations. All the calculations presented below used the benzene curves for the $\mathrm{CH}$ modes, for consistency with the calculations on PAH. The contribution of the CC modes was estimated assuming that $R_{\mathrm{CC}}=2 R_{\mathrm{CH}}$. Under this approximation, the $\mathrm{CC}$ modes give a negligible contribution to radiationless transitions in tetraphenylphorphyrins. However, in octaalkylporphyrins, where $n_{\mathrm{H}}=6, n_{\mathrm{C}}=8$ and $n_{\mathrm{X}}=24$, the number of $\mathrm{CC}$ local modes is sufficiently large to contribute to the nonradiative rate. The contribution of the $\mathrm{CC}$ local modes to the $\mathrm{S}_{1} \rightarrow \mathrm{S}_{0}$ internal conversion in octaalkylporphyrin is $2.5 \times 10^{5} \mathrm{~s}^{-1}$, whereas that of the $\mathrm{CH}$ bonds is $6.2 \times 10^{5} \mathrm{~s}^{-1}$. The experimental rate, estimated from the data published by Bonnett et al. [31], is $3.1 \times 10^{7} \mathrm{~s}^{-1}$. The differences between experimental and calculated rates may be assigned to the approximations involved in the estimate of $\Delta r_{\mathrm{CC}}$ and $\Delta r_{\mathrm{CH}}$ in these molecules, but they are of no consequence in the estimate of spin-orbit couplings.

\subsection{Spin-orbit coupling}

The description of spin-orbit coupling requires additional empirical parameters, as many as the number $n$ of chemically different sites where heavy atoms are introduced. In general, the nonadiabatic factor can be written as

$\chi=\chi_{0} \sum_{i=1}^{n}\left(1+c_{i} \xi_{i}^{2}\right)$

where $\chi_{0}$ is the nonadiabatic factor in the absence of significant spin-orbit coupling, and the coefficient $c_{i}$ measures the contribution of the heavy atom in the position $i$ to the total intersystemcrossing rate. Fig. 4 also includes the internal heavy-atom effect in $\mathrm{S}_{1} \rightarrow \mathrm{T}_{1}$ and $\mathrm{T}_{1} \rightarrow \mathrm{S}_{0}$ transitions of halogenated naphthalenes, following the analysis of Birks of the data of Ermolaev and Svitashev [54]. The experimental data were fitted with $c_{1}=10^{-4}$.

We are now in a position to calculate $k_{\text {isc }}$ for halogenated and metallated porphyrins. Fig. 5 compares calculated and experimental rates. This

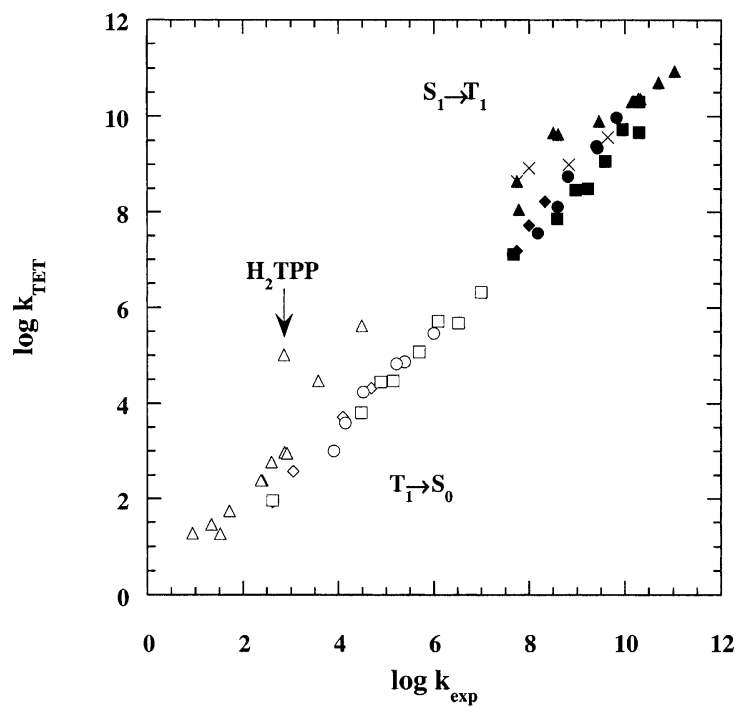

Fig. 5. Correlation between calculated and experimental radiationless transition rates in metallated tetrakisphenylporphyrins (triangles, including halogens in the phenyl rings) and halogenated porphyrins (other symbols). Diamonds represent porphyrins with halogen substituents in alkyl positions, circles $\beta$-pyrrole positions and squares in meso positions. The crosses refer to tetrakisphenylporphyrins with halogens in the phenyl rings. The filled and open symbols represent $S_{1} \rightarrow T_{1}$ and $\mathrm{T}_{1} \rightarrow \mathrm{S}_{0}$ transitions, respectively.

figure includes the porphyrins presented in Table 1, metal tetrakisphenylporphyrins [18], free-base octaalkylporphyrins having halogen substituents in alkyl, $\beta$-pyrrole and in meso positions [31]. We did not include multiple meso-fluorinated alkylporphyrins because the very strong electron withdrawing effect of this substitution pattern may alter the electronic properties of the porphyrin [1]. The heavy atom effect at different sites of the porphyrin ring can be interpreted in terms of the coefficients $c_{i}$, because they are fitted to the experimental dependence of the $k_{\text {isc }}$ on $\xi$. Table 2 collects the empirical parameters involved in these fits.

The coefficients $c_{i}$ were chosen to yield a slope close to unity in the correlation between the logarithms of calculated and experimental rates. They determine the magnitude of the electronic factor and their numerical value also depends on the Franck-Condon factor, because changing an $\mathrm{H}$ atom by a halogen atom also changes $\Delta E_{\mathrm{S}-\mathrm{T}}$ and 
Table 2

Empirical parameters fitted in the calculation of intersystem crossing rates ${ }^{\mathrm{a}}$

\begin{tabular}{|c|c|c|c|c|c|c|}
\hline & \multicolumn{3}{|l|}{$\mathrm{S}_{1} \rightarrow \mathrm{T}_{1}$} & \multicolumn{3}{|l|}{$\mathrm{T}_{1} \rightarrow \mathrm{S}_{0}$} \\
\hline & $\chi_{0}$ & $c_{1}$ & $c_{2}$ & $\chi_{0}$ & $c_{1}$ & $c_{2}$ \\
\hline Halogenated naphthalenes & $2 \times 10^{-3}$ & $10^{-4}$ & & $10^{-6}$ & $10^{-4}$ & \\
\hline $\begin{array}{l}\text { Octaalkylporphyrins halogenated in } \\
\text { alkyl positions }\end{array}$ & $10^{-2}$ & $5 \times 10^{-7}$ & & $5 \times 10^{-3}$ & $10^{-5}$ & \\
\hline $\begin{array}{l}\text { Octaalkylporphyrins halogenated in } \\
\text { alkyl pyrrole positions }\end{array}$ & $10^{-2}$ & $2 \times 10^{-5}$ & & $5 \times 10^{-3}$ & $5 \times 10^{-4}$ & \\
\hline $\begin{array}{l}\text { Octaalkylporphyrins halogenated in } \\
\text { alkyl meso positions }\end{array}$ & $10^{-2}$ & $10^{-4}$ & & $5 \times 10^{-3}$ & $10^{-3}$ & \\
\hline Metal-TPP & & & & $5 \times 10^{-3}$ & $2 \times 10^{-5}$ & \\
\hline Metal-TPP & $10^{-2}$ & $2 \times 10^{-4}$ & & $10^{-4 b}$ & $2 \times 10^{-5}$ & \\
\hline $\begin{array}{l}\text { TPP with halogens in the ortho } \\
\text { positions }^{\mathrm{c}}\end{array}$ & $10^{-2}$ & & $2 \times 10^{-6}$ & & & \\
\hline $\begin{array}{l}\text { ZnTPP with halogens in the ortho } \\
\text { positions }^{\mathrm{c}}\end{array}$ & $10^{-2}$ & $2 \times 10^{-4}$ & $2 \times 10^{-6}$ & $10^{-4 b}$ & $2 \times 10^{-5}$ & $5 \times 10^{-7}$ \\
\hline
\end{tabular}

${ }^{a}$ Room temperature, except where noted; $c_{2}$ refers to the effect of halogens in the ortho positions.

${ }^{\mathrm{b}} T=77 \mathrm{~K}$.

${ }^{\mathrm{c}}$ This work.

$\eta_{\mathrm{H}}$. The good correlation obtained in Fig. 5 results from a correct description of both electronic and Franck-Condon factors.

It is very interesting to remark that $c_{1}$ is smaller for $\mathrm{S}_{1} \rightarrow \mathrm{T}_{1}$ than for $\mathrm{T}_{1} \rightarrow \mathrm{S}_{\mathrm{o}}$ transitions when the heavy atoms are introduced in the alkyl, pyrrole and meso positions of free-base octaalkylporphyrins. This means that such heavy atoms increase more the triplet-state decay rate than its rate of formation. Ultimately, these substitution patterns will give rise to high triplet-state quantum yields, but the triplets will have short lifetimes. On the other hand, heavy metals or halogens in the ortho positions of the phenyl rings tend to increase more the triplet-state formation rate than its decay. This favours high yields of triplet without compromising the triplet lifetime. The halogens in the ortho positions are particularly remarkable, as they are 50 times more efficient in accelerating the formation of the triplet than its decay.

The efficiency of the halogen substituents at the ortho positions should be related to a favourable overlap between the orbitals of the halogen atoms and those of the porphyrin core. We investigated the electronic structure of these species performing quantum mechanical-molecular orbital calculations on a Silicon Graphics. O2
Workstation using the Cerius ${ }^{2}$ (from Molecular Simulations Incorporated-MSI) software. Geometry optimisation was performed with the Austin Model 1 with configuration interaction (AM1-CI) [55], as included in the MOPAC6.0 version. Hyperchem software (release 6.01 for Windows) was further used to obtain the frontier molecular orbitals by means of the Zerner Intermediate Neglect of Differential Overlap/1 with Configuration interaction (ZINDO/1-CI) technique. Fig. 6 shows the contours of the HOMO and LUMO calculated with the ZINDO method [56]. The highest occupied molecular orbital (HOMO) and the next-to-the highest occupied molecular orbital (HOMO-1) are mainly localised on the porphyrin moiety. The same applies to the lowest unoccupied molecular orbital (LUMO) and to nextto-the lowest occupied molecular orbital $(\mathrm{LUMO}+1)$. It is known from crystallographic data that the angle of the phenyl group with the porphyrin ring for the ZnTPP is about $60^{\circ}$ [57]. The introduction of bulky atoms in the ortho positions leads to a larger degree of rotation of the phenyl groups with respect to the plane of the porphyrin skeleton, facilitating the overlap of halogen $\mathrm{p}_{z}$-orbital with orbitals of the porphyrin moiety. 


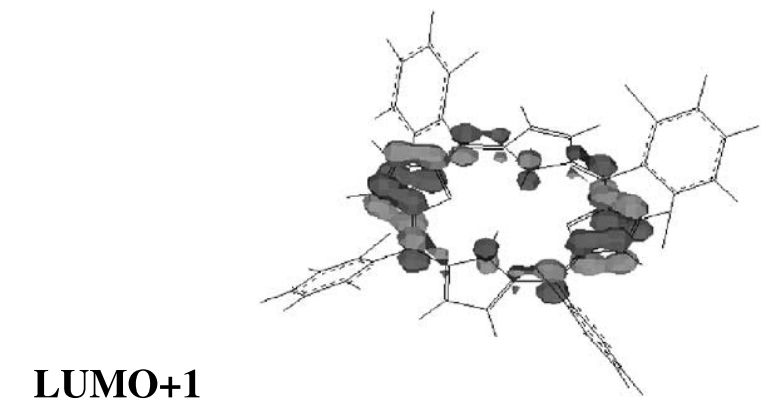

\section{LUMO}

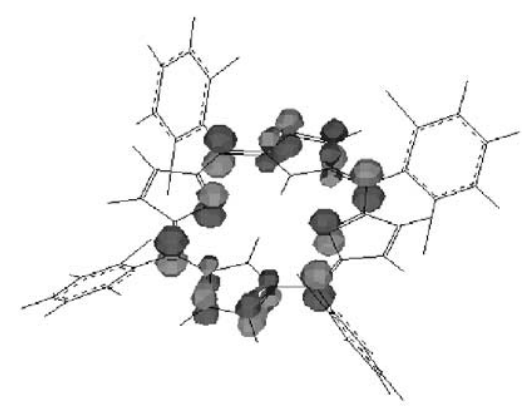

HOMO

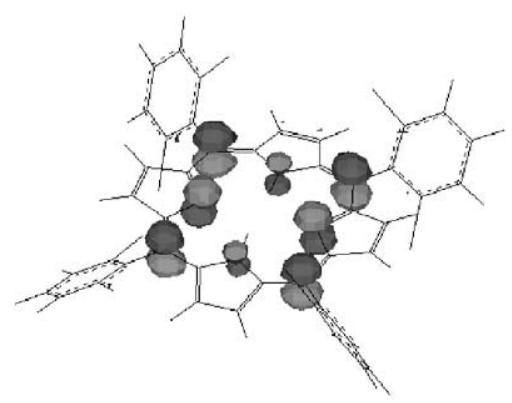

\section{HOMO-1}

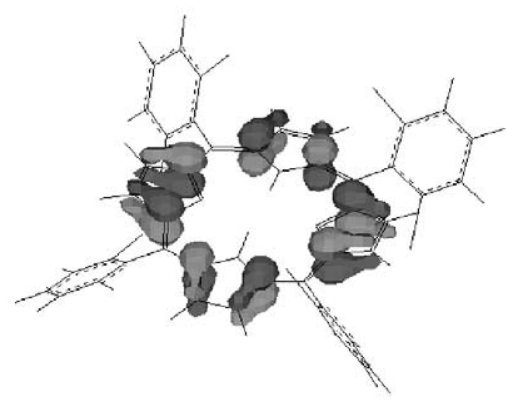

Fig. 6. LUMOs (top) and HOMOs (bottom) contours calculated with the ZINDO/1-CI method. The electron density contours show that the porphyrin core carries nearly all the electron density of these orbitals.

\section{Conclusion}

Tetrakisphenylporphyrins with halogens in the ortho positions are particularly efficient in promoting $\mathrm{S}_{1} \rightarrow \mathrm{T}_{1}$ intersystem crossing: $k_{\text {isc }}$ increases by two orders of magnitude from $\mathrm{H}_{2} \mathrm{TPP}$ to $\mathrm{H}_{2} \mathrm{TPPCl}_{8}$. On the other hand, the comparison between the low-temperature phosphorescence lifetimes of $\mathrm{ZnTPP}$ and $\mathrm{ZnTPPCl}_{8}$ reveals that the introduction of $8 \mathrm{Cl}$ atoms decreases the lifetime of the triplet state by a very modest $37 \%$. The Tunnel-Effect Theory, modified to account for spinorbit coupling, is a convenient toll to rationalise and predict heavy atom effects in radiationless transitions. The experimental data on halogenated porphyrins and metalloporphyrins and their interpretation with TET indicate that tetrakisphenylporphyrins with halogens in the ortho positions are very appropriate to generate long-lived triplet states in high yields. Such compounds may find application as singlet oxygen sensitisers, where such properties and a strong absorption in the visible and near-infrared are desirable.

\section{Acknowledgements}

We thank SAPIENS (European Union) and FCT for financial support (Project No. POCTI/ QUI/42536/2001). M.P. received a scholarship from Praxis XXI/BD/11398/97. We are grateful to Prof. Gaspar Martinho (Instituto Superior Técnico, Lisboa) for the measurement of picosecond lifetimes.

\section{References}

[1] S.I. Yang, J. Seth, J.-P. Strachan, S. Gentemann, D. Kim, D. Holten, J.S. Lindsey, D.F. Bocian, J. Porphyrins Phthalocyanines 3 (1999) 117.

[2] R. Bonnett, P. Charlesworth, B.D. Djelal, D.J. McGarvey, T.G. Truscott, J. Chem. Soc., Perkin Trans. 2 (1999) 325.

[3] J.D. Spence, T.D. Lash, J. Org. Chem. 65 (2000) 1530.

[4] L.G. Arnaut, S.J. Formosinho, J. Photochem. Photobiol. A 111 (1997) 111-139.

[5] A.J. Hudson, T. Richardson, J.P. Trirtle, R.A.W. Johnstone, A.J.F.N. Sobral, A.M.d'A. Rocha Gonsalves, Mol. Cryst. 253 (1993) 103. 
[6] M.B. Grieve, T. Richardson, R.A.W. Johnstone, A.F.N.L. Sobral, A.M.d'A. Rocha Gonsalves, Thin Solid Films 243 (1994) 581

[7] A.M.d'A.R. Gonsalves, M.M. Pereira, J. Mol. Cat. A 113 (1996) 209

[8] T.J. Dougherty, Adv. Photochem. 17 (1992) 275.

[9] T.J. Dougherty, Photochem. Photobiol. 58 (1993) 895.

[10] R. Bonnett, Chem. Soc. Rev. 24 (1995) 19.

[11] S. Rywkin, E. Ben-Hur, Z. Malik, A.m. Prince, Y.-S. Li, M.E. Kenney, N.L. Oleinik, B. Horowitz, Photochem. Photobiol. 60 (1994) 165.

[12] E. Ben-Hur, B. Horowitz, Photochem. Photobiol. 62 (1995) 383-388.

[13] M. Pineiro, A.L. Carvalho, M.M. Pereira, A.M.d.A.R. Gonsalves, L.G. Arnaut, S.J. Formosinho, Chem. Eur. J. 4 (1998) 2299.

[14] M. Pineiro, M.M. Pereira, A.M.d'A. Rocha Gonsalves, L.G. Arnaut, S.J. Formosinho, J. Photochem. Photobiol. A 138 (2001) 147.

[15] M. Pineiro, A.M.d'A. Rocha Gonsalves, M.M. Pereira, S.J. Formosinho, L.G. Arnaut, J. Phys. Chem. A 106 (2002) 3787.

[16] S.P. McGlynn, T. Azumi, M. Kinoshita, Molecular Spectroscopy of the Triplet State, Prentice-Hall, Englewood Cliffs, NJ, 1969.

[17] A. Harriman, J. Chem. Soc., Faraday Trans. 1 (76) (1980) 1978.

[18] A. Harriman, J. Chem. Soc., Faraday Trans. I 77 (1981) 369.

[19] J.R. Darwent, P. Douglas, A. Harriman, G. Porter, M.-C. Richoux, Coord. Chem. Rev. 44 (1982) 83.

[20] S.J. Formosinho, J. Chem. Soc., Faraday Trans. 2 (70) (1974) 605 .

[21] G. Stricker, V. Subramaniam, C.A.M. Seidel, A. Volkmer, J. Phys. Chem. B 103 (1999) 8612.

[22] L.G. Arnaut, R.A. Caldwell, J.E. Elbert, L.A. Melton, Rev. Sci. Instrum. 63 (1992) 5381.

[23] C.S. Soares, L.G. Arnaut, J. Phys. Chem. 104 (2000) 11075.

[24] M. Lock, Monatsh. Chem. 55 (1930) 307.

[25] J.S. Lindsey, I.C. Schreiman, H.C. Hsu, P.C. Kearny, A.M. Marguerettaz, J. Org. Chem. 52 (1987) 827.

[26] A.M.d'A. Rocha Gonsalves, J.M.T.B. Varejão, M.M Pereira, J. Heterocyclic Chem. 28 (1991) 635.

[27] J.W. Buchler, in: D. Dolphin (Ed.), The Porphyrins, vol. 1, Academic Press, New York, 1978, p. 328.

[28] A.D. Adler, F.R. Longo, F. Kampas, Inorg. Chem. 32 (1979) 2443.

[29] H.H. Hodgson, H.G. Beard, J. Chem. Soc. 127 (1925) 875.
[30] A. Harriman, J. Chem. Soc., Faraday Trans. 2 (77) (1981) 1281.

[31] R. Bonnett, A. Harriman, A.N. Kozyrev, J. Chem. Soc., Faraday Trans. 88 (1992) 763.

[32] J. Seixas de Melo, P.F. Fernandes, J. Mol. Struct. 565-566 (2001) 69.

[33] P.G. Seybold, M. Gouterman, J. Mol. Spectrosc. 31 (1969) 1.

[34] S.L. Murov, I. Carmichael, G.L. Hug, Handbook of Photochemistry, Marcel Dekker, New York, 1993.

[35] R. Englman, J. Jortner, Mol. Phys. 18 (1970) 145.

[36] O.S. Mortensen, W. Siebrand, A.W. Tarr, Chem. Phys. 125 (1988) 231.

[37] D.L. Dexter, J. Chem. Phys. 21 (1953) 836.

[38] N. Nijegorodov, R. Mabbs, Spectrochim. Acta, Part A 57 (2001) 1449.

[39] N.V. Korol'kova, V.G. Klimenko, T.A. Kir'yanova, E.A. Gastilovich, Chem. Phys. 248 (1999) 233.

[40] S.J. Formosinho, Mol. Photochem. 7 (1976) 41.

[41] J. Jortner, J. Ulstrup, Chem. Phys. Lett. 63 (1979) 236.

[42] W. Siebrand, in: A.B. Zahlan, et al. (Eds.), The Triplet State, Cambridge University Press, Cambridge, 1967, p. 31.

[43] E.F. McCoy, I.G. Ross, Aust. J. Chem. 15 (1962) 573.

[44] A. Langseth, P.B. Stoicheff, Can. J. Chem. 31 (1956) 350.

[45] J.H. Callomon, T.M. Dunn, I.M. Mills, Philos. Trans. R. Soc. London A 259 (1960) 499.

[46] S. Shaik, A. Shurki, D. Danovich, P.C. Hiberty, J. Am. Chem. Soc. 118 (1996) 666.

[47] A.A.C.C. Pais, L.G. Arnaut, S.J. Formosinho, J. Chem. Soc., Perkin Trans. 2 (1998) 2577.

[48] A.J. Gordon, R.A. Ford, The Chemist's Companion, Wiley, New York, 1972, p. 107, 114.

[49] S.J. Formosinho, L.G. Arnaut, R. Fausto, Prog. Reaction Kinet. 23 (1997) 1.

[50] S.J. Formosinho, Rev. Port. Quim. 14 (1972) 201.

[51] L.G. Arnaut, L.G. Formosinho, J. Photochem. Photobiol. A 100 (1996) 15.

[52] J.B. Birks, Photophysics of Aromatic Molecules, Wiley, London, 1970, p. 185 and p. 187.

[53] M. Kasha, Discuss. Faraday Soc. 9 (1950) 14.

[54] V.L. Ermolaev, K.K. Svitashev, Opt. Spectrosc. 7 (1959) 399.

[55] M.J.S. Dewar, R.C. Bingham, D.H. Lo, J. Am. Chem. Soc. 97 (1975) 1285.

[56] M.C. Zerner, in: D.B. Boyd (Ed.), Reviews in Computational Chemistry, VCH Publishers, New York, 1991.

[57] M.D. Glick, G.H. Cohen, J.L. Hoard, J. Am. Chem. Soc. 89 (1967) 1996. 